\title{
PEATONALIZACIÓN Y TRANSPORTE PÚBLICO. DE UN MATRIMONIO MAL AVENIDO A UNA RELACIÓN DE CONVENIENCIA
}

Sandra Matamoros Grande

Licenciada en Economía, Grupo Avanza, España

\section{RESUMEN}

Según la Carta de los derechos del peatón adoptada por el Parlamento Europeo en octubre de 1988 "El peatón tiene derecho a que ciertas zonas urbanas sean para su uso exclusivo, lo más extensas posible, y que no sean simples recintos peatonales sino que estén en relación con la organización general de la ciudad, y también el derecho a que conecten itinerarios cortos, lógicos y seguros". Desde entonces hasta ahora, en muchas ciudades españolas se han ido dando los pasos necesarios para recuperar el espacio urbano ocupado por el vehículo privado a través de procesos de peatonalización muy similares entre ellos. Avanza ha detectado que en casi la totalidad de los procesos de peatonalización llevados a cabo en las ciudades en las que gestiona el transporte público urbano se ha optado por expulsar de la "zona peatonal" a los autobuses urbanos. ¿Existe un imperativo legal que obligue a actuar de esta manera?; ¿resulta imposible que convivan peatones y autobuses en un mismo espacio?; ¿deberían aprovecharse las peatonalizaciones para mejorar el atractivo del transporte público?

En este artículo se busca una posible respuesta a estas preguntas a través de un análisis de la situación actual en las ciudades en las que está presente el Grupo Avanza, una recopilación de algunos de los pros y contras observados en los procesos de peatonalización y el análisis particular de las consecuencias de la peatonalización para la red de autobuses urbanos en la ciudad de Huesca.

\section{PEATONALIZACIÓN: LA AMBIGÜEDAD DEL TÉRMINO}

La Dirección General de Tráfico (D.G.T) establece en su Catálogo de señales verticales de circulación tres categorías de vías peatonalizadas en función de la afluencia de viandantes y del grado de restricción al tráfico rodado:

- Zonas 30: hay una afluencia media de peatones, hay ciertos obstáculos para limitar la velocidad de los vehículos, puede haber aparcamientos en los laterales y segregación de la calzada - acera.

- Vías de prioridad peatonal: la afluencia de peatones es mayor, la velocidad máxima es de $20 \mathrm{~km} / \mathrm{h}$ y para limitarla se introduce mobiliario urbano o sentidos de circulación concurrentes. Si existe aparcamiento este tendrá una señalización específica y no hay segregación entre acera y calzada.

- Vías peatonales: la afluencia de peatones es muy alta o casi exclusiva, hay controles de 
acceso y las limitaciones de velocidad son muy restrictivas, fijándose el máximo en $10 \mathrm{~km} / \mathrm{h}$ y adaptándose siempre al flujo de peatones. Si existe aparcamiento este tendrá una señalización específica y no hay segregación entre acera y calzada.

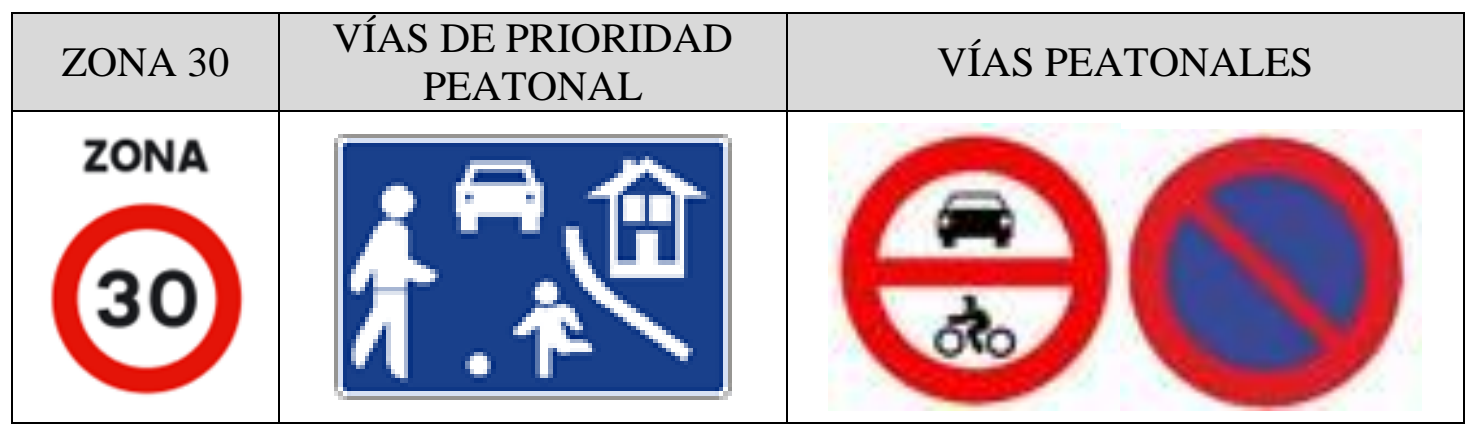

Fig. 1 - Señales del Catálogo de señales verticales de circulación de la D.G.T.

La no existencia aparente de un reglamento supramunicipal, además del citado catálogo, que regule y tipifique qué es y cuáles son las condiciones para que una calle se considere peatonal, provoca que sean los municipios, a través de sus ordenanzas reguladoras, los que definan las características en sus ciudades.

Así, nos encontramos casos donde la regulación está muy desarrollada y otros donde apenas se menciona al peatón y su relación con el entorno. Sin ánimo de exhaustividad y a muestra de ejemplo, se citan a continuación definiciones de varias ordenanzas:

- En Madrid se definen las áreas estanciales, y dentro de éstas se distinguen varios tipos de zonas. Se agrupan a continuación las tipologías recogidas en la Ordenanza de Diseño y Gestión de Obras en la Vía Pública del Ayuntamiento de Madrid de 2006:

- Bulevares, sendas, plazas y otros espacios peatonales, constituidos por aquellos espacios prohibidos al tráfico rodado, salvo, en horas especiales, a los vehículos de servicio y emergencia.

- Calles peatonales donde sólo se permite el acceso de vehículos de emergencia y, en horarios especiales, a los vehículos de servicio y mantenimiento y, en su caso, a los vehículos de los residentes.

- Calles de prioridad peatonal en las que se permite el paso de automóviles, siempre que éstos se muevan a velocidades compatibles con el tránsito y la estancia de los peatones.

- En la modificación de 2007 de la Ordenança Municipal Reguladora de la Circulació De Persones I Vehicles En Les Vies Urbanes de Terrassa se definen las "islas de peatones" como aquellas zonas de la ciudad en las cuales está prohibido total o parcialmente el tránsito rodado, de manera que las vías públicas comprendidas en estas zonas quedan reservadas para la circulación de peatones. Los vehículos calificados como de servicio público (SP) no están afectados por estas restricciones y podrán acceder libremente a las zonas respetando la prioridad de paso de los vehículos respecto a los vehículos.

- En la Ordenanza General de Tráfico del Excmo. Ayuntamiento de Zaragoza de 2004 se establece:

- Calle peatonal, como una vía pública de uso preferentemente peatonal sin 
diferenciación entre calzada y aceras donde se permite una circulación limitada de vehículos a un máximo de $10 \mathrm{~km} / \mathrm{h}$, concediéndose siempre la prioridad a los peatones, aunque éstos no deberán estorbar inútilmente a los vehículos.

- Calle de tráfico restringido, como una vía pública donde hay una limitación cuantitativamente importante en el acceso de vehículos, permitiéndose solamente a una minoría en función de su uso, necesidad u horario, aunque no existe otra limitación en la velocidad que la genérica en zona urbana y la que debe adoptar todo conductor para adecuarse a las condiciones de circulación.

- En Benidorm, el Ayuntamiento en la Ordenanza municipal № 1de Movilidad de 2014 determina zonas de acceso restringido dentro del casco urbano, a las que sólo podrán acceder los vehículos autorizados bajo ciertas condiciones y en determinados días y franjas horarias, mediante la concesión de autorizaciones para el acceso y permanencia de vehículos en dichas zonas y sin sobrepasar la velocidad de $20 \mathrm{~km} / \mathrm{h}$.

- En la Ordenanza General de Tráfico del Ayuntamiento de 2013 de Huesca, se definen plazas, paseos, bulevares y calles peatonales como áreas destinadas al reposo de los peatones y a la defensa ambiental, con acondicionamiento vegetal opcional, y en las que el tráfico peatonal está segregado de la circulación rodada. Las calles o zonas urbanizadas como de uso peatonal clasificadas como calles peatonales, calles de tráfico restringido o zonas peatonales y señalizadas con prohibición de circulación con las excepciones que en el texto complementario de la señal se indique, necesitarán un permiso especial de circulación para aquellos vehículos que pretendan acceder a ellas. No necesitan esta autorización los autobuses de transporte colectivo urbano y los de transporte interurbano, tanto regular como discrecional.

Este análisis permite extraer dos conclusiones principales respecto a la regulación de las "zonas peatonales" en las ciudades estudiadas:

- La falta de una regulación común provoca que exista un elevado nivel de heterogeneidad en la definición de una figura aparentemente tan generalizada y homogeneizada como las zonas peatonales. Cada ciudad interpretada e incluso denomina de manera diferente lo que entiende como tal en sus respectivas ordenanzas o normas reguladoras de la vía pública. A lo largo de este artículo seguiremos refiriéndonos a "zonas peatonales" a falta de una terminología común y estandarizada más precisa.

- Frente a esta falta de uniformidad, no se ha encontrado ninguna alusión en la normativa consultada que prohíba o recomiende la expulsión de las redes de transporte público de las "zonas peatonales".

\section{PROCESOS DE PEATONALIZACIÓN EN LAS CIUDADES CON TRANSPORTE PÚBLICO GESTIONADO POR EL GRUPO AVANZA}

Avanza es el primer operador privado de servicios de transporte urbano de España, con un modelo integral de movilidad urbana que gestiona sistemas de autobuses, bicicletas y tranvías. Está presente a lo largo de todo el territorio y gestiona el transporte urbano de casi 
30 ciudades en la Península Ibérica.

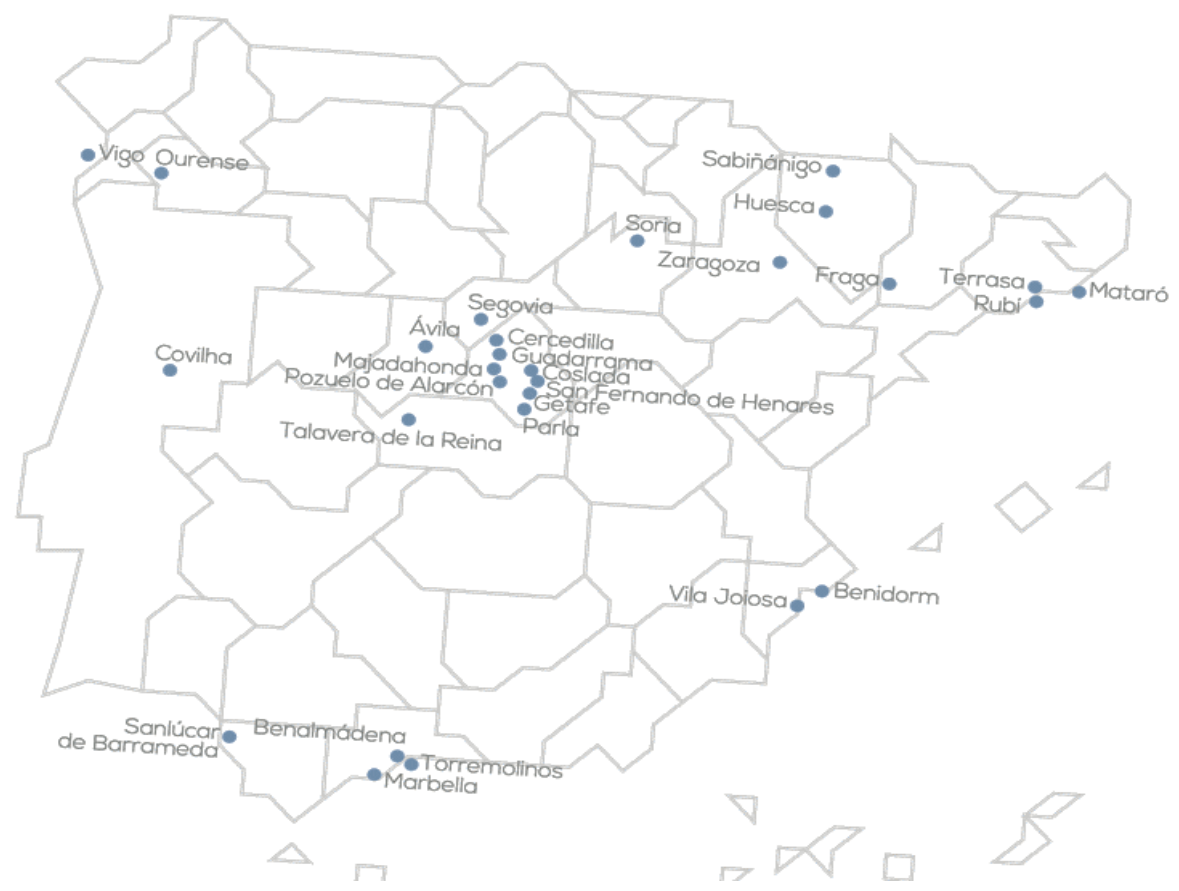

\section{Fig. 2 - Localización de las ciudades operadas por Avanza}

Desde esta posición, Avanza participa en la planificación de la movilidad urbana ayudando a las Administraciones Públicas a alcanzar sus objetivos de sostenibilidad, aumentando el número de viajeros y mejorando la satisfacción de los mismos. Las ciudades en las que está presente el Grupo Avanza difieren tanto en su tamaño (Zaragoza y Ávila), como en su ubicación (Vigo y Sanlúcar de Barrameda) así como en la tipología de tejido urbano de la ciudad (Benidorm y Huesca). Pese a las evidentes diferencias existentes entre ellas, todas las ciudades donde opera Avanza tienen alguna zona o calle peatonalizada de mayor o menor dimensión y en ninguna de ellas está permitido el acceso a los autobuses, salvo excepciones como:

- Benidorm: Se ha peatonalizado el paseo marítimo de poniente, una vía de sentido único en primera línea de playa, donde, en esta primera fase de peatonalización, está permitido el paso de los autobuses públicos a falta de definir una alternativa razonable de circulación sin pérdida de cobertura para los viajeros.

- Segovia: Desde 2007 circula por la calle peatonal Fernandez Ladreda un autobús eléctrico conectando el casco antiguo de la ciudad con los puntos de interés más relevantes.

- Huesca: Donde, tal y como se explica más adelante en este texto, el trasporte urbano de la ciudad tiene permitido el acceso a la plaza Navarra, dentro del área peatonal de la ciudad.

Por tanto podemos afirmar que el $90 \%$ de las zonas peatonales de las ciudades en las que Avanza gestiona el transporte público urbano se ha optado por no permitir el desarrollo de 
la red de autobuses en dichas áreas.

\section{PROS Y CONTRAS DE LA PEATONALIZACIÓN}

Una ciudad con zonas peatonales conlleva ciertos beneficios para los ciudadanos, entre ellos destacan:

- Autonomía en la movilidad para todos los individuos y equidad en el reparto del espacio público.

- Devolución del espacio público a los niños (desarrollándose personalmente o creando la posibilidad de definir caminos al colegio) y a los colectivos más vulnerables frente a los espacios en los que la presencia del vehículo privado es mayor con la consiguiente mejora en la calidad de vida, de la autonomía y del desarrollo de dichas personas

- Humanización de los espacios públicos favoreciendo las relaciones entre los habitantes de las ciudades y su calidad de vida.

- Reducción de la contaminación acústica y atmosférica en el interior de la zona peatonal y, si hay un traspaso modal a modos blandos como consecuencia de la peatonalización, también en el conjunto de la cuidad.

- Reducción de la congestión y los problemas de aparcamiento en las zonas peatonales que, normalmente, son centros históricos con un entramado de calles complejo.

En sentido contrario, los problemas que pueden derivarse de una peatonalización son:

- Gentrificación de las zonas con la consiguiente expulsión de los residentes más vulnerables económicamente.

- Uso de ocio y turístico exclusivo derivado de la falta de equipamiento o dotaciones en la zona que la convierten en un destino de ocio exclusivamente y no en una zona para la estancia y el disfrute de sus residentes que sufrirán un excesivo ruido ambiental en noches y fines de semana.

- Uso comercial excesivo que conlleva inseguridad en horarios nocturnos por la falta de más actividades diferentes.

- Creación de islas no conectadas con el resto de la ciudad que no favorecen el tejido urbano.

- Tratamiento de los bordes: En los límites de las zonas peatonales se crean situaciones anómalas derivadas de la interrupción de un área con unas características muy diferenciadas del resto de la ciudad (aparcamiento, empobrecimiento y degradación, incremento del tráfico...)

- Dificultades para la coexistencia con modos blandos como las bicis y el transporte público.

- Problemas para las personas mayores o de movilidad reducida cuando la peatonalización conlleve una pérdida de accesibilidad.

- Tratamiento de las zonas, horarios y procedimientos de la carga y descarga.

- Las actuaciones de los servicios de emergencia en el desarrollo de los planes de 
contingencias necesarios pueden verse afectados por extensas zonas peatonales.

Algunos de estos aspectos en contra de los procesos de peatonalización (como la gentrificación, el tratamiento de los bordes o el tejido urbano no conectado) podrían estár relacionados con la expulsión de los autobuses de las zonas peatonales y podrían evitarse en cierta medida con una planificación del transporte urbano en el conjunto de la ciudad.

También cabe destacar que la presencia de autobuses urbanos en zonas peatonales podría disminuir uno de los principales beneficios de la peatonalización de una zona como es la reducción de emisiones y ruidos, y es aquí donde encontramos que reside parte del origen de la generalización de la medida de restricción absoluta del tráfico de autobuses en zonas peatonales.

\section{ANÁlisis CRÍTICO DE LAS CONSECUENCIAS DEL PROCESO DE PEATONALIZACIÓN EN HUESCA}

El Plan de Movilidad Urbano Sostenible de Huesca, ciudad con más de 52.000 habitantes, recogía la necesidad de elaborar un Plan de Peatonalización de la ciudad.

Entre los años 2012 y 2014 se comenzó con la implantación de las medidas marcadas en el plan (aumento del número de plazas de zona azul, aumento de km de vías ciclistas, creación de una ordenanza de movilidad...) y, tras una serie de reuniones en las que intervinieron representantes de todos los sectores de la ciudad, se finalizó el plan peatonalizando la zona centro, controlando el acceso de vehículos con cámaras y cambiando el diseño de la red de transporte público, expulsando a los autobuses del casco antiguo peatonalizado.

Con la peatonalización, la circulación de tráfico rodado quedó prohibida en la zona salvo para residentes (con controles por cámara), servicios de emergencia y, excepcionalmente, para el servicio de transporte público, el cual tiene permitido el acceso hasta un punto concreto, la plaza de Navarra, que conforma el centro neurálgico de la ciudad.

La red de transporte público en funcionamiento antes de la peatonalización atravesaba la ciudad de este a oeste por los cosos dotando a la zona centro de una buena cobertura, siendo deficitaria en la zona noreste de la ciudad. 


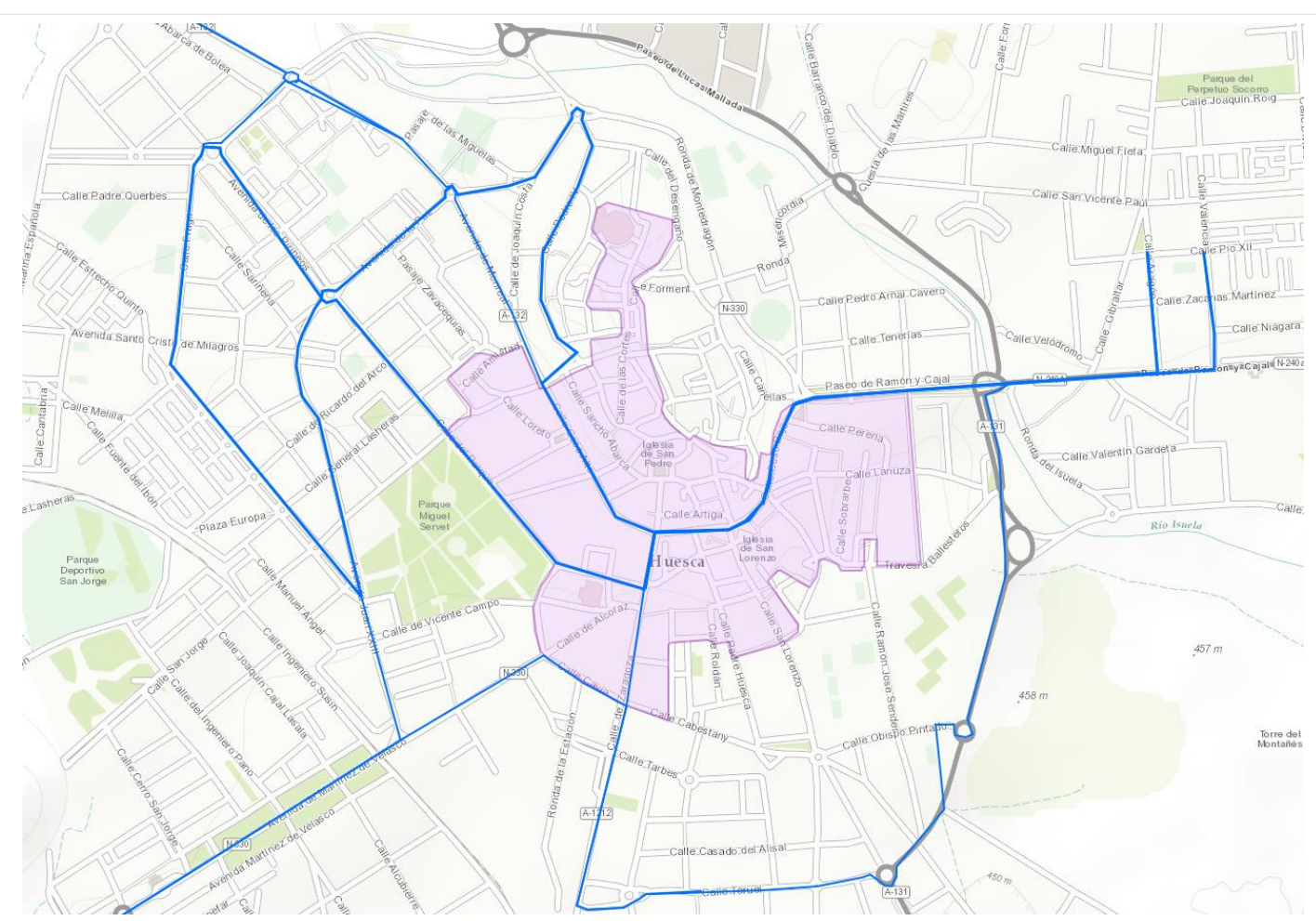

Fig. 3 - Red de transporte de Huesca anterior a la peatonalización y zona peatonal actual.

Actualmente, la red de transporte de Huesca está formada por tres líneas circulares que recorren las principales vías de circunvalación del centro peatonal, acercándose al casco antiguo cuando el viario y las restricciones de tráfico rodado lo permiten. 


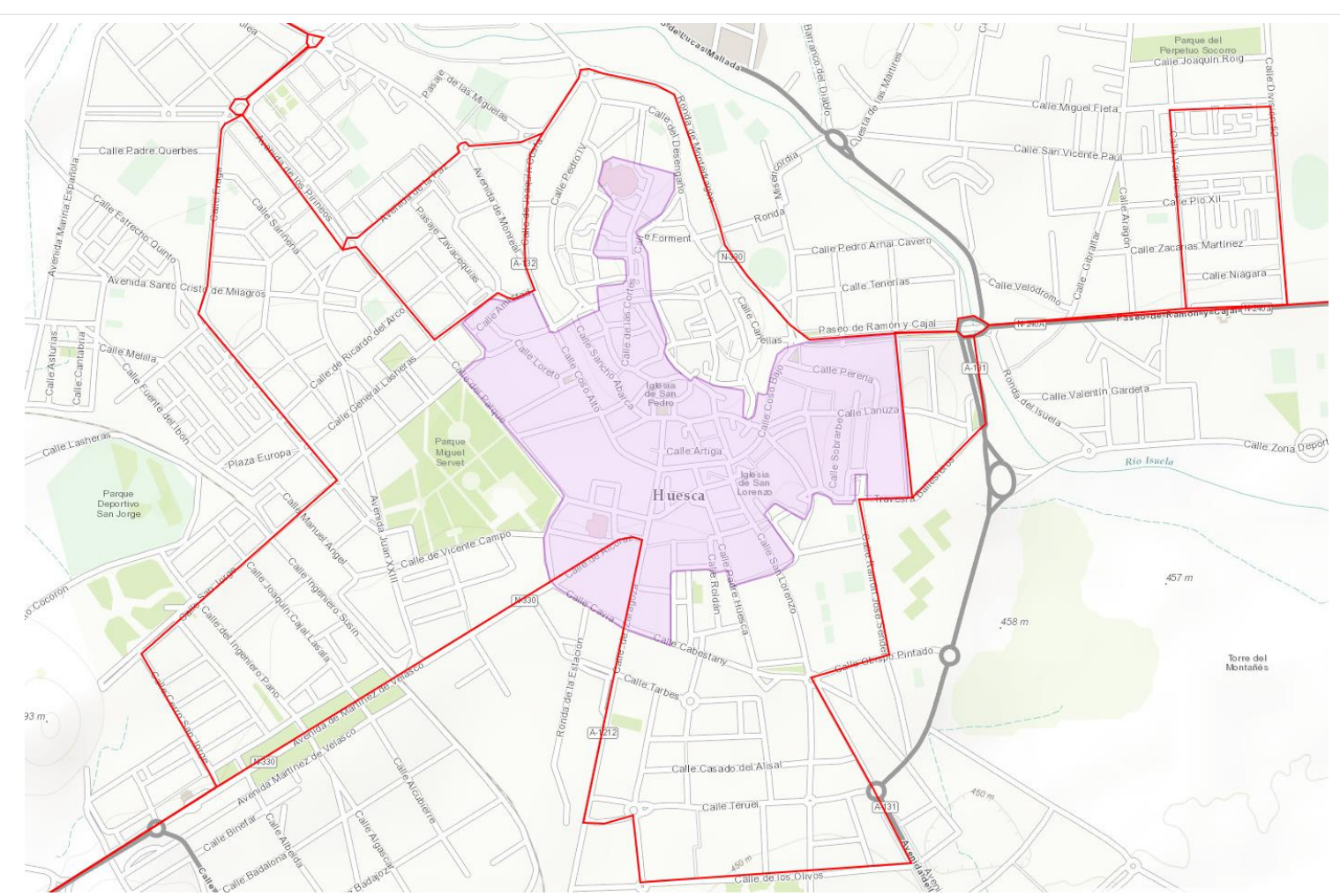

Fig. 4 - Red de transporte de Huesca posterior a la peatonalización y zona peatonal actual.

La zona peatonalizada abarca un amplio espectro de usos del suelo, es una zona comercial importante en la ciudad, pero también aloja numerosas viviendas, mayoritariamente de piso bajo y antiguas.

Los efectos de la peatonalización se dejan notar en una revitalización del sector comercial en la zona y en un incremento, según los estudios realizados dentro de las actualizaciones del Plan de Movilidad de la ciudad, del número de desplazamientos a pie, en bicicleta y transporte público, en detrimento del uso del vehículo privado.

Realizaremos un análisis del nivel de accesibilidad a la red de autobuses dentro del área peatonal, para ello:

1. Identificamos un área de influencia de las paradas de autobús como aquella en la que es posible acceder a una parada en menos de 5 minutos a pie (considerando una velocidad de desplazamiento a pie estándar de $5 \mathrm{~km} / \mathrm{hora}$ ). 


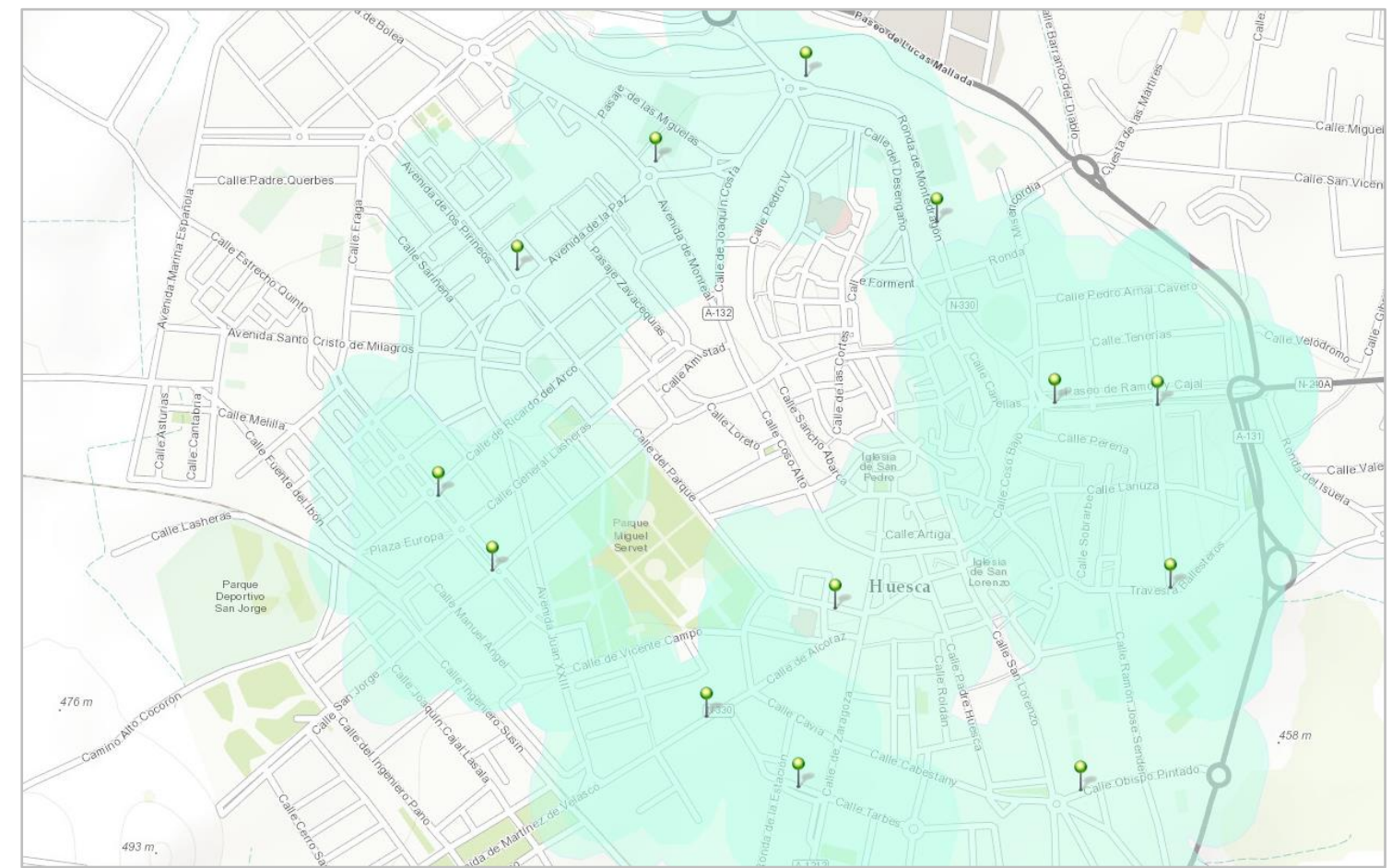

Fig. 2 - Área de influencia a pie ( 5 min) desde las paradas de autobús cercanas al centro peatonal

2. Cruzamos el área generada con la delimitación del área peatonal.

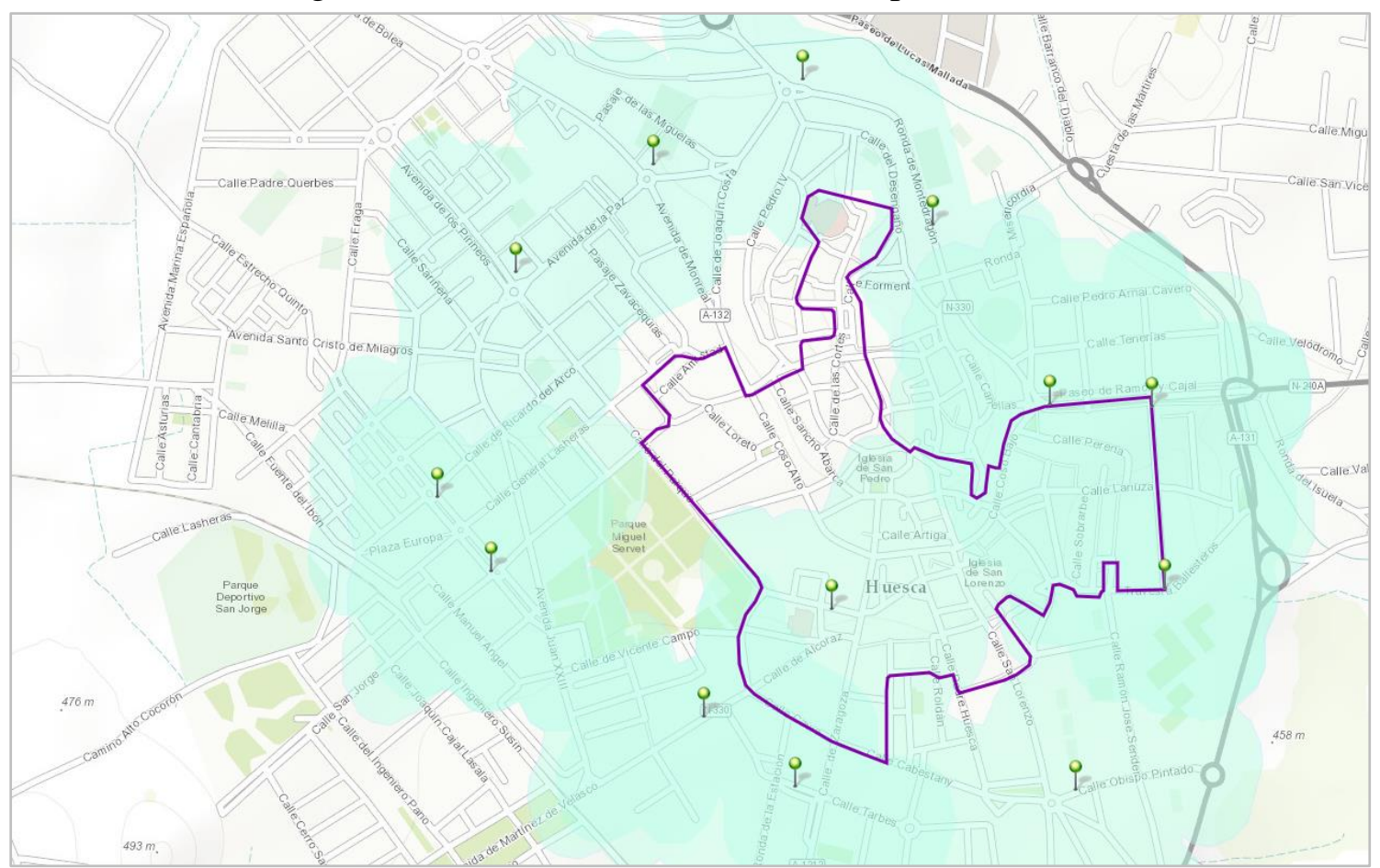

Fig. 3 - Área de influencia a pie ( 5 min) desde las paradas de autobús y zona peatonal 
3. Se crea una zona fuera del área de influencia de las paradas de autobuses y dentro de la zona peatonal, es decir, sin posibilidad de acceso más que a pie o en bicicleta, que afecta a más de 2.778 habitantes de los cuales 620 (el 23\%) son personas de más de 60 años. Estas personas antes podían acceder a la zona en autobús en menos de 5 minutos y ahora no.

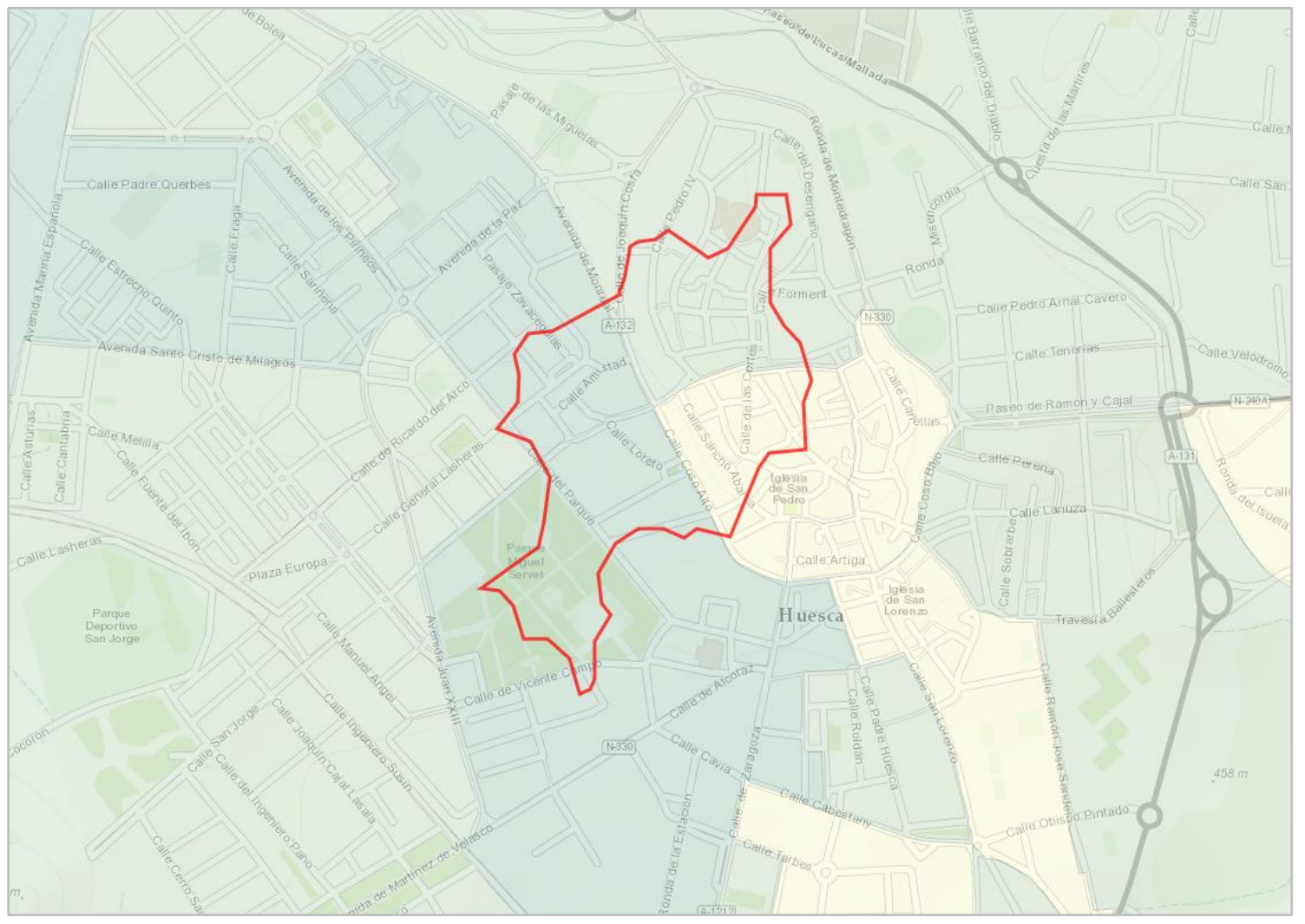

Fig. 3 - Zona fuera del área de influencia de las paradas de autobuses y número de personas mayores de 60 años por sección censal

\section{CONCLUSIONES}

El análisis realizado sobre el tratamiento del transporte público en las "zonas peatonales" de las ciudades en las que el Grupo Avanza está presente confirma que en la mayoría de las ciudades (al menos un 90\% de ellas) se opta por expulsar de las zonas peatonales no solo al vehículo privado sino también a los autobuses urbanos. Esta posición homogénea contrasta con el hecho de que no existe una regulación común para dichas zonas y en la normativa estudiada particular de cada ciudad, no existe ningún tipo de recomendación u obligación en este sentido.

La revisión de las posiciones a favor y en contra de la peatonalización de zonas permite identificar como uno de los de los posibles motivos para optar por no permitir el desarrollo de redes de transporte público de autobuses en zonas peatonales el hecho de que hacerlo eliminaría o reduciría uno de los principales beneficios de este tipo de zonas: es la reducción de emisiones y ruidos. Sin embargo existen maneras de paliar este inconveniente:

- Uso de vehículos de gas o híbridos cuyo nivel de emisiones es muy inferior a los de combustibles fósiles y compatibles con los niveles estándares en este tipo de áreas. 
- Se puede restringir el paso de autobuses a determinadas horas y a vías menos vulnerables de la zona ( transitadas, entre otros). Se trataría de una solución homogénea con la que se le da al tratamiento de la carga y descarga en estas zonas.

En el caso de Huesca se han identificado y cuantificado algunos de los principales inconvenientes derivados de la expulsión del transporte público de este tipo de zonas:

- Existe un grupo de personas residentes en la zona fuera del área de influencia de las paradas de autobuses y dentro del área peatonal que se convierte en un colectivo de riesgo por su perfil demográfico, que antes no existía.

- La puesta en marcha de soluciones para este colectivo se convierte en una difícil tarea: a la hora de realizar estudios de movilidad es difícil que se detecte esta carencia puesto que será un colectivo aislado, con escasa movilidad, que no será encuestado en las campañas comunes con la frecuencia que sus necesidades exigen.

Se hace necesario que los Ayuntamientos y agentes implicados en la gestión de la movilidad de manera directa o indirecta (consultores, operadores, técnicos o asociaciones) replanteen las soluciones dadas a las redes de transporte público urbano de superficie en las nuevas zonas peatonales, buscando la solución más adecuada para cada ciudad en función de sus necesidades particulares y del tipo de población residente en dichas zonas.

Desde el punto de vista de la movilidad, la creación de zonas peatonales exclusivas, sin convivencia con ningún otro modo, si bien son zonas donde los peatones ven reconocidos sus derechos de circulación de manera cómoda y segura, pueden quedar aisladas del entramado urbano, provocando una pérdida de estos mismos derechos en el exterior zona peatonal.

Avanza, como operador de referencia en redes de transporte urbano, considera que no debe perderse la oportunidad de fortalecer el atractivo del transporte público en los procesos de peatonalización para impulsar el trasvase de viajes del vehículo privado al transporte público. 